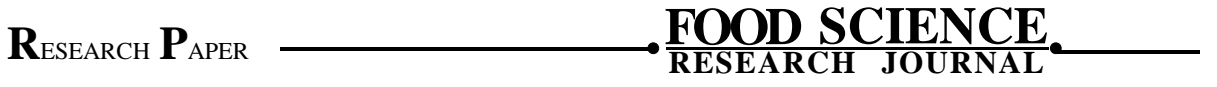

e ISSN-2230-9403 — Visit us :

www.researchjournal.co.in

Volume 8 | Issue 1| April, 2017 | 14-20

DOI : 10.15740/HAS/FSRJ/8.1/14-20

\title{
Utilization of whole grain cereal flours and honey in preparation of extruded products
}

\author{
Hanuman Bobade and Savita Sharma
}

\begin{abstract}
This paper explores the possibility of utilizing the whole grain cereal flours along with honey in preparation of quality extruded products. Flours of whole wheat, brown rice, whole maize in single and in combination (3:4:3) were mixed with 10 per cent honey and extrusion was carried out at various optimized feed moisture and temperature levels to produce extruded snacks, breakfast cereals and porridge. The extruded products were evaluated for different quality characteristics including anti-oxidant activity and total phenolics content. The various products did not show significant variations in quality attributes, however, cereals had marked influence in determining the quality of these extruded products. Extruded products prepared from cereal flours in combination resulted in better physical properties followed by extruded products prepared from maize flour. With respect to the phenolics content and antioxidant activity, extruded products prepared from maize flour showed better results than extruded products prepared from other cereal flours. The whole wheat flour showed its least suitability in preparation of extruded products.
\end{abstract}

Key Words : Extruded products, Whole grain cereal flour, Honey, Antioxidant activity, Total phenolic content

How to cite this article : Bobade, Hanuman and Sharma, Savita (2017). Utilization of whole grain cereal flours and honey in preparation of extruded products. Food Sci. Res. J., 8(1): 14-20, DOI : 10.15740/HAS/FSRJ/8.1/14-20.

Associate Authors' :

SAVITA SHARMA, Department of Food Science and Technology, Punjab Agricultural University, LUDHIANA (PUNJAB) INDIA 